\title{
Correspondence
}

\section{Identifying terror suspects: the role of psychiatrists}

On 22 July 2011, Anders Behring Breivik carried out the worst attacks in Norwegian history since the Second World War, killing 77 men, women and children and injuring another 151 people. In November 2011 he was declared to have paranoid schizophrenia by a court-appointed panel of forensic psychiatrists. ${ }^{1}$ Breivik's diagnosis evokes memories of Nicky Reilly, who has Asperger syndrome and was convicted of trying to blow up a shopping centre in Exeter in May 2008, and Andrew Ibrahim, a former drug addict who was jailed for making a bomb at his flat in Bristol in April 2008. ${ }^{2}$

The notion that most forms of terrorism are an understandable (if not condonable) reaction to limitations on freedom and equality has lost ground in many countries. As psychiatrist Gerrold Post pointed out, 'there is a broad spectrum of terrorist groups and organizations, each of which has a different psychology, motivation and decision making structure. Indeed, one should not speak of terrorist psychology in the singular, but rather of terrorist psychologies' ${ }^{3}$ Terrorist violence most often is deliberate (not impulsive), strategic and instrumental; it is linked to and justified by ideological, for example political or religious, objectives. In Breivik's case, his stated objective was to 'defend Europe against a Muslim invasion', ${ }^{1}$ which is now being considered as part of a wellformed delusional belief system. These issues all add complexity to the construction of terrorism as a form of violence and stretch the limits of present-day clinical risk assessment.

In recent guidance, the UK Home Office requested an increased role from the UK medical professionals in identifying people at risk of committing future terrorist acts. ${ }^{4}$ This raises a number of ethical and professional considerations which are particularly relevant to psychiatrists, given an almost certain role which might be expected from the profession in not only identifying, but treating and risk-managing terror suspects. The following four questions are pertinent in this regard.

1. Would an enhanced role in identifying and referring terror suspects as suggested by the Home Office leave the profession losing patients' trust in psychiatrists' professionalism and patients' confidentiality, as suggested by some? ${ }^{5}$

2. How would the public protection be balanced with the individual patient freedom in an environment of ever-increasing public protection and aversion to risk?

3. Even if psychiatrists agree to move to the forefront in the war against terror, how would our currently relatively unsophisticated arsenal of risk assessment tools detect and quantify such a complex, lowfrequency and constantly changing threat?

4. The elusive question, 'Is terrorism a mental disorder?' remains unanswered and many would continue to challenge the psychiatrists' role in identifying, and potentially managing, terrorist suspects.

In our view, with the terrorist threat remaining as one of the major public protection issues for the foreseeable future, these questions will become more pertinent. The profession should without delay embark on an open and honest discussion on its role in this crucial public protection issue, and develop a clear view.

1 BBC News. Who, What, Why: How do you assess a killer's mental health? 29 November 2011 (http//www.BBC.co.uk/news/magazine15928316).

2 Dyer C. Doctors will be asked to help identify people becoming terrorists. BMJ 2011; 342: d3627.

3 Post J. The Mind of the Terrorist: Individual and Group Psychology of Terrorist Behavior. Testimony prepared for the Subcommittee on Emerging Threats and Capabilities, Senate Armed Services Committee, USA, 15 November 2011.

4 Home Office. Counter-Terrorism Strategy (CONTEST). Home Office, 2011 (http//www.home office.gov.UK/publications/counter-terrorismstrategy/).

5 English P. Doctors should not agree to identify potential terrorists. BMJ 2011; 343: d4211.

Dumindu Witharana is Specialty Registrar (ST6) in Forensic Psychiatry, email: duminduwitharana@nhs.net, and Olumuyiwa John Olumoroti is Consultant Forensic Psychiatrist, both at Springfield University Hospital, London, UK; Fintan Larkin is Consultant Forensic Psychiatrist, Personality Disorder Directorate, Broadmoor Hospital, Berkshire, UK.

doi: 10.1192/pb.36.4.155

\section{Time to reform fitness to plead?}

The Law Commission published their comprehensive review of current fitness to plead provisions in 2011 and recommendations on the issue are expected later this year. ${ }^{1}$ Notwithstanding the regularity with which reports addressing the issue of fitness to plead are requested of psychiatrists, there remains a lack of clarity on the subject. The legal test still derives from a case in $1836(R \vee \text { Prichard })^{2}$ and there is general agreement among psychiatrists and legal professionals that the presently accepted requirements are far from adequate. Whereas these 'Prichard criteria' broadly set out the requirement for the accused to be able to enter a plea, understand the evidence against them, instruct their solicitor, follow court proceedings, and challenge a juror, in many cases it is far from clear what threshold these requirements are measured against.

To what extent does a mild intellectual disability or autism-spectrum disorder render someone unfit to plead or stand trial? We know that rates of intellectual disability are relatively high in convicted offenders; does that mean most of them are to be considered legally unfit? Is that actually in the interests of justice or the individual? Although arguably it is for the court to decide, a great deal of weight is often placed on the expert witness report and it falls to the psychiatrist to consider these questions. Efforts have been made to introduce a standardised test for fitness to plead, ${ }^{3}$ yet none has been universally accepted. It is incumbent on courts to adopt special measures to assist vulnerable defendants to participate in proceedings; if such measures can be considered sufficient for children, does this extend to adults?

The rationale for the provisions under Prichard is to protect the vulnerable and avoid subjecting those with mental 
disorder to unjust criminal justice proceedings which they cannot understand or fully participate in. Where an accused is deemed unable to do any one of these then he or she should be considered unfit to plead and can be dealt with under the Criminal Procedure (Insanity and Unfitness to Plead) Act 1991, usually by holding a trial of the facts and then, if convicted, considering disposal options such as a hospital order, supervision or an absolute discharge.

The fundamental principle of an individual's right to defend themselves should not be undermined without proper consideration. On the other hand, many professionals are of the opinion that the current system sets too high a threshold with the result that too few mentally disordered offenders are found unfit to plead. ${ }^{4}$ In the USA, around $10 \%$ of offenders are considered to 'lack competence to stand', but in England and Wales that figure is much lower. ${ }^{1}$ One of the reasons for this is that, strictly speaking, the current criteria focus almost exclusively on cognitive ability rather than decision-making capacity, with little account being paid to suggestibility, memory impairment, the ability to give evidence in court, the impact of psychosis or of cultural barriers.

In their report, the Law Commission propose a new legal test much more closely aligned with the capacity test recently enshrined in the Mental Capacity Act 2005. ${ }^{1}$ Under the new provisions an accused would need to demonstrate that they understood the information relevant to the decisions that he or she would have to make in the course of the trial, retain that information, use or weigh that information as part of the decision-making process and communicate his or her decisions. Such a test should be acceptable to psychiatrists, as it simplifies the requirements and largely mirrors the capacity test with which we are all now familiar. However, such a change could have significant cost and resource implications. The new system could see many more people assessed by psychiatrists and any corresponding increase in compulsory admissions could have a significant impact on forensic services, although the cost might be offset by a reduced number of custodial sentences. The Law Commission's final recommendations, expected later this year, are anticipated with great interest.

1 Law Commission. Unfitness to Plead (Consultation Paper No 197). Law Commission, 2010

$2 R \vee$ Prichard (1836) 7 C \& P 303

3 Akinkunmi AA. The MacArthur Competence Assessment Tool - Fitness to Plead: a preliminary evaluation of a research instrument for assessing fitness to plead in England and Wales. J Am Acad Psychiatry Law 2002; 30: $476-82$.

4 Rogers TP, Blackwood N, Farnham F, Pickup G, Watts M. Reformulating the law on fitness to plead: a qualitative study. J Forensic Psychiatry Psychol 2009; 20: 815-34.

Liz Tate, Specialty Registrar in Forensic Psychiatry, Wessex Deanery, Fareham, UK, email: liztate@doctors.org.uk

doi: $10.1192 / \mathrm{pb} .36 .4 .155 \mathrm{a}$

\section{Exposure to psychiatry in foundation years may improve recruitment and retention}

On reading the article by Barras \& Harris, ${ }^{1}$ I recognised one of the trainee's comments as my own. This comment was written merely weeks into my core trainee year 1 and related to the reaction of hospital consultants to my choosing psychiatry as a career (during my foundation 2 year, FY2). I would like to elaborate further on my experience as a foundation trainee in acute hospital medicine relating to psychiatry, and suggest what improvements could be made to the current system to boost recruitment and retention.

When I was an FY2 trainee, I was keen for the opportunity to undertake a 4-month rotation in psychiatry. Despite stating this preference, I was not allocated to the specialty and instead I completed FY2 jobs in accident and emergency, orthopaedics and intensive care. Although I was initially disappointed with this combination, it proved to be an extremely valuable learning opportunity which enabled me to realise and understand the vast overlap between psychiatry and acute hospital specialties. I observed trauma patients during my orthopaedic job who had sustained massive injuries from 'failed' suicide attempts. I saw numerous psychiatric presentations in the accident and emergency department. Even intensive care provided me with chances to understand the consequences of psychiatric illness, ranging from irreversible hypoxic brain damage following hanging in a patient with depression to endstage liver failure in a patient with alcohol dependence.

Many medical students and foundation doctors who have enjoyed the acute hospital setting during their foundation years may be reluctant to consider a specialty such as psychiatry. This may be particularly true if they have not worked in a psychiatric specialty during this time. Perhaps a solution would be to encourage deaneries to provide 3-month foundation posts instead of 4-month posts, so as more foundation doctors are exposed to psychiatry. It would also be worth considering whether these posts should be partly hospital based and have a particular emphasis on liaison psychiatry, so that foundation trainees can observe directly the important role of the psychiatrist in working collaboratively with medical colleagues. Barras \& Harris noted that $5.0 \%$ of trainees had stated they had considered leaving psychiatry because they wished they worked in a different specialty. ${ }^{1}$ At this time when retention rates are falling, perhaps enabling foundation doctors to see for themselves the diversity of psychiatry and how it integrates with acute hospital medicine is key.

1 Barras C, Harris J. Psychiatry recruited you, but will it retain you? Survey of trainees' opinions. Psychiatrist 2012; 36: 71-7.

Dineka Gray, CT3 trainee, Mersey Care NHS Trust, Liverpool, UK, email: dinekag@doctors.org.uk

doi: $10.1192 / p b .36 .4 .156$

\section{Revealing our religion/atheism in the witness box}

I gave evidence in a criminal court recently about one of my in-patients, with the patient watching from the dock. When the clerk asked me, 'Do you have a religion?', I answered 'No' and was given the words to read to make a solemn affirmation ('I do solemnly, sincerely and truly declare and affirm that the evidence which I shall give, shall be the truth, the whole truth and nothing but the truth'), rather than taking the oath ('I swear by Almighty God that the evidence... .' $)^{a}$ on a religious text. So

a. The Oaths Act 1978 directs that the oath/solemn affirmation shall start 'I swear by Almighty God that'/'I do solemnly, sincerely and truly declare and affirm that', 'followed by the words of the oath prescribed by law'. The words to follow cannot be found elsewhere in the Act, in another statute or in the rules of the court. In 1927 the King's Bench Judges approved the following form of oath for use in civil and criminal courts: 'the evidence, which I shall give, shall be the truth, the whole truth and nothing but the truth'. This is still in use today. 